\title{
REGISTROS DA TECTÔNICA BRASILIANA NA REGIÃO DE GUANHÃES (SE, BRASIL): DEFORMAÇÃO E METAMORFISMO DAS ROCHAS DE IDADE PÓS-TRANSAMAZÔNICA
}

\author{
Tania M. Dussin*, Patrícia Duarte, Ivo A. Dussin
}

\begin{abstract}
Paleoproterozoic granitoids $(\sim 1,7 \mathrm{Ga})$ intrude gneisses and migmatites of the tonalitic-trondjemiticgranodioritic basement of the Neoproterozoic Araçuaí fold-thrust belt in the Guanhães region (Minas Gerais).Previous studies attributed deformation and metamorphism of the country rocks to the Paleoproterozoic Transamazonian Event. The role of the younger Brasiliano Event is not well understood and different interpretations have been postulated. Post-Transamazonian rocks, recently identified in the region, are deformed and metamorphosed. The deformation is complex, with a ductil character increasing to east. The associated metamorphism reach the amphibolite facies, with migmatitic remobilization, and granitogenesis at about $540 \mathrm{Ma}$. The available data suggest that after the Transamazonian event the Guanhães region underwent granitogenesis, deformation, metamorphose in the course of the Neoproterozoic Brasiliano Event.
\end{abstract}

\section{INTRODUÇÃO}

A região de Guanhães localiza-se a leste da Cordilheira do Espinhaço, na porção central de Minas Gerais, e está inserida na faixa neoproterozóica Araçuaí, a qual delimita, a sudeste, o Craton São Francisco. Os efeitos da orogênese brasiliana, no domínio da Faixa Araçuaí, se traduzem por uma deformação regional que cresce progressivamente em direção a leste, atingindo condições rúptil-dúcteis na porção oriental da Cordilheira do Espinhaço e rúpteis a não deformadas em direção ao interior do cráton, a oeste. O metamorfismo associado processou-se nas condições da fácies xisto-verde.

A geologia da região de Guanhães é dominada por rochas gnaissificadas e migmatizadas da associação tonalito-trondjemito-granodiorito que constituem o embasamento regional. A deformação polifásica destes terrenos gnáissicos é complexa e inexistem estudos sistemáticos na região que permitam agrupar e associar estruturas e paragêneses metamórficas a eventos tectônicos específicos. Com base nos poucos dados disponíveis, a evolução tectônica regional tem sido interpretada como principalmente relacionada à orogênese transamazônica.

Entretanto, novos trabalhos realizados na região têm disponibilizados dados, sobretudo geocronológicos, que permitiram a identificação de grupos de rochas de idades pós-transamazônicas que representam um notável laboratório natural para o estudo das características da tectônica brasiliana, uma vez que foram afetados unicamente por este evento. Este trabalho apresenta dados sôbre a deformação e metamorfismo destas rochas, com o objetivo de evidenciar a atuação e aspectos da evolução tectônica brasiliana na região.

\section{CONTEXTO GEOLÓGICO}

O embasamento da Faixa Araçuaí e do Supergrupo Espinhaço é representado por terrenos gnáissicograníticos que foram sujeitos a extenso retrabalhamento e metamorfismo durante os eventos proterozóicos. Estas rochas foram englobadas, sob a designação geral de Complexo Gnáissico-granítico por Almeida \& Litiwinski (1984). A denominação engloba o conjunto dominado por gnaisses para- e orto-derivados, diversamente migmatisados e milonitisados, retrabalhados nos eventos Transamazônico e Brasiliano e remanescentes de terrenos tipo granito-grenstone. $\mathrm{O}$ complexo aflora a sul, sudeste e leste da Serra do Espinhaço Meridional e no interior desta nos núcleos erodidos de grandes anticlinórios (Fig.1). Estas diferentes áreas de ocorrência receberam as denominações locais de Complexo Guanhães, Gouveia e Porteirinha, respectivamente, no Mapa Geológico de Minas Gerais (Pedrosa Soares et al. 1994).

$\mathrm{O}$ acervo de dados geológicos e geocronológicos para estas extensas áreas é muito mais restrito que aqueles disponíveis para o complexo gnáissico do 


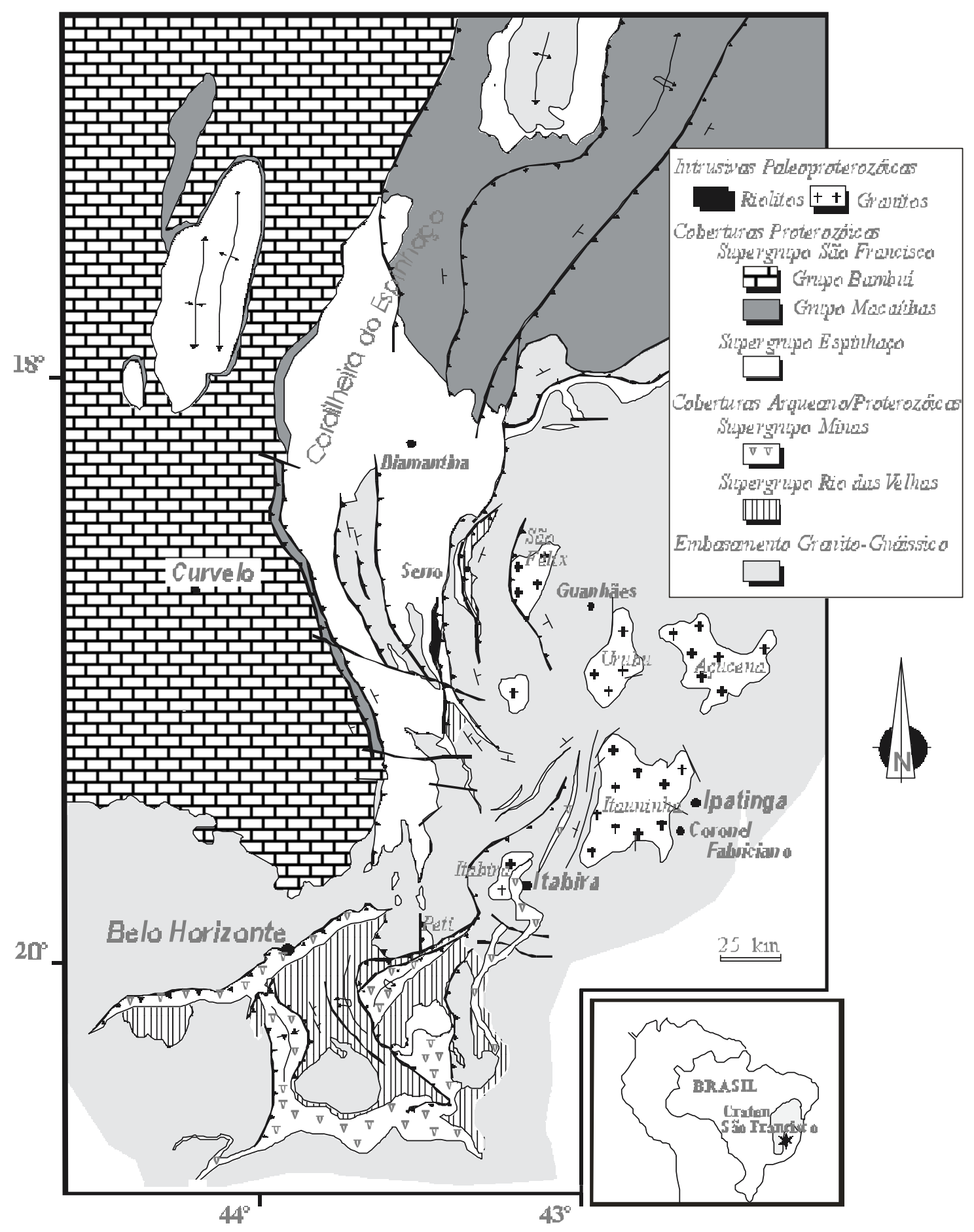

Figura 1. Mapa esquemático das regiões do Espinhaço Meridional e Quadrilátero Ferrífero, borda sudeste do Craton São Francisco. Modificado de Schobbenhaus et al. (1984).

Figure 1. Schematic map of southern Espinhaço and Quadrilátero Ferrífero, southeastern border of São Francisco craton. After Schobbenhaus et al. (1984).

Quadrilátero Ferrífero e das regiões mais ao sul, e grandes incertezas persistem no que tange à cartografia, relações das unidades litológicas originais, idade e características dos eventos tectono-magmáticos que as afetaram e na separação dos fragmentos crustais arqueanos daqueles terrenos de diversas idades resultantes de acresção proterozóica.

Em sua zona de ocorrência mais oriental, o
Complexo Guanhães tem como litologia mais característica gnaisses migmatisados em graus diversos, que variam de isótropos a finamente bandados. Sequências vulcano-sedimentares, metamorfisadas na fácies anfibolito, ocorrem como faixas estreitas e descontínuas intercaladas no complexo gnáissico. São constituídas por xistos máficos e ultramáficos, formações ferríferas, rochas cálcio-silicáticas, metapelitos e quartzitos (Grossi Sad et al. 1989). 
No Complexo Guanhães, as características da deformação são heterogêneas. Em sua porção mais ocidental, o Complexo está tectonicamente sobreposto aos metassedimentos do Supergrupo Espinhaço que constui a unidade dominante na cordilheira homônima. A deformação é penetrativa de caráter rúptil-dúctil, associada a um transporte de massas para oeste. Registros de etapas de deformação mais antigas estão preservados só localmente e muitas vezes são completamente obliterados. Em direção a leste, a deformação torna-se dúctil e a separação entre a deformação e metamorfismo atribuíveis à tectônica brasiliana e a eventos mais antigos não é clara.

O conhecimento geocronológico sobre o Complexo está restrito a um pequeno número de determinações $\mathrm{Rb} / \mathrm{Sr}$ e K/Ar em gnaisses e metassedimentos intercalados. $\mathrm{O}$ conjunto de dados disponíveis indica que o Complexo Guanhães é uma porção de crosta essencialmente transamazônica. Uma isócrona $\mathrm{Rb} / \mathrm{Sr}$ de referência baseada em determinações sôbre as litologias gnáissicas indica idade de $1801 \pm 70 \mathrm{Ma}$ ( $\mathrm{Ri}=0,709 \pm 0,003$; dados de Brito Neves et al. 1979). Esta idade é corroborada por determinações $\mathrm{Sm} / \mathrm{Nd}$ nos granitos Borrachudos intrusivos no complexo gnáissico, para os quais os estudos geoquímicos indicam derivação a partir da crosta transamazônica, com limitada participação de fontes mais antigas (Dussin, T.M. 1994; Dussin et al. 1997). Idades Rb/Sr mais antigas, em tôrno de 2,66 Ga (Müller et al. 1986; Teixeira et al. 1990), foram localmente obtidas para o complexo. As isócronas referentes são, entretanto, de má qualidade e os dados obtidos são passíveis de re-interpretação. A maior parte dos resultados disponíveis, entretanto, indicam idades variáveis entre 1400 e 480 Ma, e são interpretadas como idades brasilianas ou rejuvenescimento de idades mais antigas com perdas isotópicas parciais no Brasiliano (Teixeira et al. 1990).

Com base em dados geológicos então disponíveis, Teixeira et al. (1990) e Dussin, I.A (1994) interpretaram a atuação da tectônica brasiliana na porção oriental do Complexo Guanhães como relativamente restrita, entendendo a região como um bloco crustal de comportamento relativamente rígido durante a orogênese brasiliana.

\section{DEFORMAÇÃO E METAMORFISMO DAS ROCHAS DE IDADES PÓS- TRANSAMAZÔNICAS}

Face à complexidade do arcabouço estrutural do Complexo Guanhães, a identificação de grupos de rochas de idades pós-transamazônicas nele intrusivas ou a ele sobrepostas, constituem elementos-chaves à caracterização da tectônica brasiliana na região, uma vez que aquelas foram afetadas exclusivamente por este evento. Três grupos litológicos de idades póstransamazônicas mostram deformação e metamorfismo exclusivamente brasilianos: (a) granitos da Suíte Borrachudos, (b) Sequência Vulcano-Sedimentar do
Alto Guanhães, (c) granitos e migmatitos neoproterozóicos.

\section{Granitos da Suíte Borrachudos}

A Suíte Borrachudos compreende um conjunto de rochas vulcânicas e corpos graníticos do tipo A (Dussin, T.M. 1994) que intrudiram o Complexo Guanhães em torno de 1,7 Ga (Dossin et al., 1993). Os granitos mostram grande homogeneidade litológica. São rochas de grão médio a grosso, foliadas, com microclínio como principal mineral constituinte, quartzo, albita, hastingsita e biotita, além de magnetita, alanita e fluorita como acessórios. São granitos subsolvus, metaluminosos a peraluminosos com altas concentrações de $\mathrm{SiO}_{2}, \mathrm{~K}, \mathrm{~K} /$ $\mathrm{Na}, \mathrm{Fe}, \mathrm{F}, \mathrm{Nb}, \mathrm{Y}, \mathrm{Zr}$, Ga e elementos terras raras.

Às feições magmáticas dos granitos Borrachudos estão superimpostas estruturas de deformação e recristalização metamórfica brasilianas. $\mathrm{O}$ metamorfismo gerou hastingsita e/ou anita, fortemente orientadas gerando uma marcante foliação gnáissica, com formação local de mobilizados migmatíticos. O retrabalhamento brasiliano produziu deformação heterogênea nos plutons, com um carater dúctil crescente em direção a leste.

Um estudo mais detalhado das estruturas de deformação dos plutons Borrachudos foi realizado na região entre Itabira e Ipatinga, a sul da Cidade de Guanhães (Duarte \& Nunes 1997). Os granitos aí mostram uma variação na direção da foliação, que é de N-N10E com mergulho para E-SE na localidade de Itabira, até uma persistente foliação paralela ao bandamento gnáissico com direção geral N10E a N10W e mergulhos para W. Localmente, uma foliação milonítica de direção geral N60-90E, e mergulhos para $\mathrm{N}-\mathrm{NW}$, com desenvolvimento de superfícies $\mathrm{S} / \mathrm{C}$ pode ser observada. Lineações de estiramento mineral ocorrem associadas a estas foliações, e são reconhecidas principalmente pelo estiramento do quartzo, da biotita, e secundariamente do feldspato.

Em suas áreas de ocorrência mais orientais, especialmente próximo a Ipatinga, os plutons mostram deformação de caráter mais dúctil. Ao microscópio os minerais granulares apresentam lamelas de geminação deformadas, cristais rotacionados com sombras de pressão, formando uma textura do tipo augen ganisse. Em alguns cristais de microclínio foram observadas fraturas antitéticas à direção da deformação local. Nestas porções mais dúcteis ocorrem dobras que variam de assimétricas apertadas a isoclinais às vezes transpostas, com eixos paralelos à lineação de estiramento. A expressão da lineação de estiramento pode ser tal que L-tectonitos são gerados.

Grandes falhas de direção geral NE/SW e mergulhos variando de $30^{\circ}$ a $90^{\circ}$ para NW cortam o complexo e os granitos Borrachudos. Foram reconhecidas na região de Santa Maria de Itabira, como rampas de empurrões frontais, definidas pela lineação de estiramento mineral down dip à foliação gnáissica, e colocam as litologias do complexo basal sobre os granitos Borrachudos. 


\section{Sequência Vulcano-Sedimentar do Alto Rio Guanhães}

A leste da cidade de Guanhães, falhas inversas de baixo ângulo e direcionamento geral NNE-SSW se estendem da região de Itabira para norte passando pela localidade de Senhora do Porto. Em sua porção setentrional estes lineamentos, coincidem com o curso do Alto Rio Guanhães e encaixam uma sequência vulcano-sedimentar localmente com dezenas de metros de espessura. A seqüência é constituída por metassedimentos representados por itabiritos, quartzitos ferruginosos, xistos micáceos e quartzosos, grafita xistos, e rochas metamáficas deformadas.

A sequiência está em contato tectônico por falhas inversas de alto ângulo com o embasamento da bacia, sendo superposta por litologias do Complexo Basal a leste e sobreposta aos granitos da Suíte Borrachudos (Pluton São Félix) a oeste (Danderfer \& Meireles 1987). Uma foliação penetrativa, muitas vezes de natureza milonítica, orientada N25E e subverticalizada, está representada em todas as litologias da seqüência. A lineação contida na foliação, representada pelo alinhamento de anfibólios, biotita, e rods de quartzo, tem orientação e caimento variados. São observados ainda foliação $\mathrm{S} / \mathrm{C}$, rotação de cristais e sombra de pressão.

As paragêneses metamórficas representadas por actinolita, tremolita e hornblenda nas metamáficas e por cianita-estaurolita-granada \pm biotita nas litologias xistosas, indicam que o metamorfismo associado atingiu o fácies anfibolito inferior.

Estudos isotópicos de uma intercalação anfibolítica da sequência indicam idades de cristalização de $1697 \pm 10 \mathrm{Ma}\left({ }^{207} \mathrm{~Pb} /{ }^{206} \mathrm{~Pb}\right.$ em zircões, Dussin et al. 2000 a). Este resultado é interpretado como idade da seqüência, indicando correlação desta com o Supergrupo Espinhaço e evidenciando que os processos de fraturamento crustal, sedimentação e vulcanismo no final do Paleoproterozóico estenderam-se para leste, muito além do que fora previamente registrado.

\section{Granitos e Migmatitos Neoproterozóicos}

Condições de alto metamorfismo vigentes na orogênese brasiliana são constatáveis pela existência de mobilizados migmatíticos no embasamento gnáissico e nos granitos Borrachudos. No Pluton Morro do Urubu (Suíte Borrachudos), a sudoeste da cidade de Guanhães, determinações $\mathrm{U} / \mathrm{Pb}$ forneceram uma linha discórdia com intercepto superior a $1770 \pm 30 \mathrm{Ma}$ interpretada como idade da cristalização magmática e intercepto inferior a $620 \mathrm{Ma}$, interpretado como idade da anatexia (Fernandes et al. 2000). Uma idade de 512 \pm 15 Ma havia sido anteriormante obtida por Machado et al. (1989, $\mathrm{U} / \mathrm{Pb}$ em zircão) para remobilizados migmatíticos da localidade de Senhora do Pôrto.

Intrusões graníticas são largamente representadas nos setores setentrional e oriental da Faixa Araçuaí, mas granitos neoproterozóicos só foram reconhecidos na região de Guanhães recentemente. A sul da Cidade de Guanhães, próximo à Mina de Mirandinha, o estudo isotópico de um sienogranito, com microclínio, plagioclásio zonado com composição albita-oligoclásio, quartzo, biotita e muscovita, sem deformação e sem metamorfismo significativos, registrou idades de 536 \pm 4 Ma interpretada como cristalização magmática $\left({ }^{207} \mathrm{~Pb} /\right.$ ${ }^{206} \mathrm{~Pb}$ em zircões, Dussin et al. 2000 b).

As características estruturais, dados geoquímicos e idade de cristalização do pluton, são consistentes com as características de magmas intrudidos durante o estágio pós-colisional da orogênese brasiliana, descritas no cinturão.

\section{CONCLUSÕES}

A interpretação do Complexo Guanhães como uma entidade transamazônica é coerente com o modelo de desenvolvimento de um cinturão desta idade em posição marginal à plataforma arqueana. Este cenário encontrase bem exposto no extremo sul do Cráton São Francisco, onde a arquitetura paleoproterozóica está melhor preservada. A crosta arqueana, representada por terrenos granito-greenstone e gnaisses de alto grau, está injetada por diversos granitóides transamazônicos, parte destes com assinatura isotópica indicando a contribuição de material juvenil paleoproterozóico (Teixeira et al. 1989, Teixeira \& Figueiredo 1991).

Entretanto, os novos dados indicam a necessidade de uma re-interpretação do papel da orogênese brasiliana na região.

A deformação das rochas e sequências, hoje datadas como pós-transamazônicas, é de natureza complexa. Os registros brasilianos estão superpostos aos transamazônicos nas rochas do embasamento, e a separação entre eles não é clara.

As paragêneses minerais neoformadas indicam que o metamorfismo associado à orogênese brasiliana atingiu a fácies anfibolito inferior (zona da estaurolita), na porção ocidental do complexo (Seqüência VulcanoSedimentar do Alto Rio Guanhães), a anfibolito superior com mobilização migmatítica (gnaissificação e migmatização dos granitos Borrachudos). A intrusão de granitos de características pós-tectônicas em torno de 540 Ma parece estar vinculada à formação de um conjunto de pegmatitos e veios hidrotermais mineralizados que corta o Complexo Guanhães. Esta idéia é coerente com o modelo proposto para a região da província pegmatítica do leste mineiro e áreas adjacentes, de existência de um período metalogenético entre 530 e $500 \mathrm{MA}$, relacionado à granitogênese póscolisional da Orogênese Brasiliano (Pedrosa-Soares et al. 2000).

Portanto, os novos dados disponíveis argumentam contra a interpretação de que a região de Guanhães atuou como um bloco rígido durante a Orogênese Brasiliana, e indicam, para este período, uma evolução através de retrabalhamento, de uma porção crustal previamente deformada durante a orogênese Transamazônica, no Paleoproterozóico. 


\section{AGRADECIMENTOS}

Às agências financiadoras CNPq, CAPES e FAPEMIG, e ao CPMTC/Instituto de Geociências da Universidade Federal de Minas Gerais.

\section{REFERÊNCIAS}

Almeida F.F.M. \& Litwinski N. 1984. Província Mantiqueira, Setor Setentrional. In: Almeida F.F.M. \& Hasui Y. (Eds.) O PréCambriano do Brasil. São Paulo, Edgar Blücher Ltda., 282$307 \mathrm{p}$.

Brito Neves B.B.; Kawashita K. \& Delhal J. 1979. A evolução geocronológica da Cordilheira do Espinhaço: dados novos e integração. Rev. Bras. Geociências, 9(1):71-85.

Danderfer A., Meireles H.P. 1987. Mapeamento Geológico da Região do Alto Rio Guanhães (MG). CGE/Instituto de Geociências, Univ. Fed. Minas Gerais, Diamantina. Monografia de graduação, $80 \mathrm{p}$.

Dossin I. A., Dossin T. M., Charvet, J., Cocherie A. \& Rossi P., 1993. Single-zircon dating by step-wise $\mathrm{Pb}$-evaporation of Middle Proterozoic magmatism in the Espinhaço Range, southeastern São Francisco Craton (Minas Gerais, Brazil). In: SBG, Simp. Craton São Francisco, Salvador, Anais, 1:39-42.

Duarte P., Nunes F.S. 1997. Geologia Da Região De ItauninhaSanta Maria de Itabira - Minas Gerais. Instituto de Geociências, Univ. Fed. Minas Gerais, Belo Horizonte. Monografia de graduação, 71p.

Dussin I. A. 1994. Evolution Structurale De La Partie Méridionale de l'Espinhaço sur la bordure orientale du Craton São Francisco, Minas Gerais - Brésil: Un exemple de tectonique protérozoüque superposé. Lab. Geologie Structurale, Univ. Orléans, Orléans, Tese de Doutoramento, 200 p.

Dussin T. M., 1994. Associations plutono-volcaniques de l'Espinhaço méridional (SE-Brésil): un exemple d'évolution de la croûte protérozö̈que. Lab. Geologie Structurale, Univ. Orléans, Orléans, Tese de Doutoramento, 177 p.

Dussin T.M., Dussin I.A., Noce C.M. 1997. Tectonic settig and origin of the Mesoproterozoic Borrachudos granites (MG, Brazil). In: South-American Symp. on Isotope Geology, 1, São Paulo, Anais, 1:104-106.

Dussin T.M., Dussin I.A., Macambira M.J.B. 2000a. Chronology of Mesoproterozoic Guanhães River Sequence: ${ }^{207} \mathrm{~Pb} /{ }^{206} \mathrm{~Pb}$ Single Zircon Evaporation Data of Metavolcanic Rocks (Minas Gerais, Brazil). In: Inter. Geol. Congress, Rio de Janeiro, Abstracts Vol., CD.
Dussin T.M, Dussin I.A., Macambira M.J.B. 2000b. Chronology of Neoproterozoic Magmatism in Guanhães Region: ${ }^{207} \mathrm{~Pb} /{ }^{206} \mathrm{~Pb}$ Single Zircon Evaporation Data of Alkaline Granite (Minas Gerais, Brazil). In: Inter. Geol. Congress, Rio de Janeiro, Abstracts Vol., CD.

Fernandes M.I.S., Pedrosa Soares A.C., Noce C.M., Wiedeman C. \& Correia Neves J.M. 2000. U-Pb Geochronology of the Borrachudos Suite: Evidence of Brasiliano Tectonism Recorded by Late Paleoproterozoic Anorogenic Granites (Araçuaí Belt, Minas Gerais, Brazil). In: Inter. Geological Congress, Rio de Janeiro, Abstracts Volume, CD.

Grossi Sad J:H., Magalhães J.M.M., Carelos P.M. 1989. Geologia do Distrito de Guanhães, Minas Gerais. Belo Horizonte. Relatório Interno DOCEGEO-GEOSOL, 252p.

Machado N., Schrank A., Abreu F. R., Knauer L. G. \& Almeida Abreu P. A., 1989. Resultados preliminares da geocronologia $\mathrm{U} / \mathrm{Pb}$ na Serra do Espinhaço Meridional. In: SBG, Simp. Geol. Núcleo M.G., 5, e Simp. Geol. Núcleo Brasília, 1, Belo Horizonte, Anais, 1:171-174.

Müller G., Hohndorf A., Lauenstein H.J., Lenz H. 1986. Petrological and geochemical data on a high-metamorphic Archean BIFbearing rock sequence near Guanhães, Minas Gerais, Brazil. Gel. $J b$., D79:3-20.

Pedrosa-Soares A.C., Dardenne M.A., Hasui Y., Castro F.D.C., Carvalho M.V.A., Reis A.C. 1994. Mapa Geológico do Estado de Minas Gerais, escala 1:1.000.000. Belo Horizonte, Brazil, Companhia Mineradora de Minas Gerais.

Pedrosa-Soares A.C., Lobato L.M., Noce C.M. 2000. Cambrian pegmatitic and hydrothermal mineral deposits: the last mineralization record prior to the south atlantic opening in eastern Brazil. In: Inter. Geol. Congress, Rio de Janeiro, Abstracts Vol., CD.

Schobbenhaus C., Campos D.A., Derze G.R., Asmus H.E. 1984. Mapa Geológico do Brasil e da Área Oceânica Adjacente. Ministério das Minas e Energia/DNPM, Brasília, Brazil.

Teixeira W., Dossin I.A., Dossin T.M., Salvador E.D., Siga Jr. O., Sato K. 1990. Interpretação do Contexto Geotectônico do embasamento na borda leste do sistema Espinhaço, região de Guanhães e Gouveia-MG, com base numa integração do seu conjunto geocronológico U/Pb, Rb/Sr e K/Ar. In: SBG, ong. Bras. Geol., 36, Natal, Anais, 6:2711-2722.

Teixeira W., Tassinari C.C.G., Cordani U.G., Kawashita K. 1989. A review of the geochronology of the Amazonian craton tectonic implications. Precambrian Res., 42:213-227.

Teixeira W. \& Figueiredo M.C.H. 1991. An outline of Early Proterozoic crustal evolution in the São Francisco craton, Brazil: a review. Precambrian Res., 53:1-22. 